\title{
Using Ergometer and Timing Activities in Determining the Manpower Required in Chosen Units of Laboratory in the Shiraz Faghihi Hospital
}

\author{
Tahereh Shafaghat ${ }^{1}$, Emmanuel Ajuluchukwu Ugwa ${ }^{2}$, Kofi Aduo-Adjei ${ }^{3}$, Mohammad-Kazem Rahimi-Zarchi ${ }^{1}$, \\ ${ }^{1}$ School of Management and Medical Information, Shiraz University of Medical Sciences, Shiraz, Iran \\ ${ }^{2}$ Obstetrics/Gynecology Department, Federal Medical Centre, Birnin Kudu, Jigawa State, Nigeria \\ ${ }^{3}$ Department of Public Administration and Health Services Management, Business School, University of Ghana, Accra, Ghana
}

*Corresponding Author: Mohammad-Kazem Rahimi-Zarchi, Ph.D. Candidate of Health Services Management, School of Management and Medical Information, Shiraz University of Medical Sciences, Shiraz, Iran. Tel: +98-9132529084, Email: rahimi_99@yahoo.com

Received: 5 Oct. 2015; Accepted: 18 Nov. 2015; Online Published: 11 Jan. 2016

\begin{abstract}
Background: The quantity and quality of manpower, especially in health systems, are major factors affecting speed of service delivery, cost, and accuracy, or, in other words, the quality of service.

Objective: This study purposed to investigate the manpower required in various units of the laboratory at Shiraz Faghihi Hospital.

Methods: This is a cross-sectional and descriptive-analytical research conducted on all testing processes in the fields of parasitology, hormone biology, microbiology, and urinalysis performed at the studied hospital. The Westinghouse ergometer and timing method was used to estimate manpower requirements, and SPSS $_{18}$ software was used to analyze data.

Results: The average standard time of every duty cycle in parasitology units, hormone biology, microbiology, and urinalysis are $12,5,9$, and 5 minutes, respectively. The numbers of human resources required in said units were estimated to be $2.6,3,4$, and 3.7 respectively. In parasitology unit there is lack of 1 manpower. In hormone unit there are two manpower surpluses. In biology unit there is one manpower surplus and urinalysis unit is estimated to be proportional to the number of troops.

Conclusion: It is suggested that new, scientific tools be used to evaluate the status of department staff and make improvements to avoid the high costs and difficulties that manpower shortages and surpluses cause for the organization.
\end{abstract}

Keywords: Ergometer, Health Manpower, Laboratories, Hospital Units

\section{Background}

All organizations focus on manpower as a valuable factor in helping them achieve their goals [1]. Manpower is one of the most important system resources in providing health care, because of the use of health technology in management and provision of services to promote health is the duty of the manpower in health care systems [2]. Because of the importance of the human dimension in development in the recent years, many countries have emphasized human stock in their development programs [3]. Among service organizations, hospital systems are among the most costly organizations, and thus, manpower has particular importance for them. Improving efficiency and productivity at a hospital requires effective planning for the application of human resources and the efficient use of resources and time [4]. According to a World Health Organization report, hospitals in third world countries allocate themselves about half of the national costs in the health sector. The hospitals' share of government expenditures in the health sector is between $60 \%$ and $80 \%$ [5]. Personnel expenses usually account for $60 \%$ to $80 \%$ of all current expenditures spent on the health sector. Therefore, considering the nature of this sector, inadequate training and use of manpower is a waste of resources and will negatively affect the health of a society [3]. Because of the constraint of human resources in hospitals and the quantity and quality of human resources, these areas are considered major factors affecting the speed of service delivery, costs, and the accuracy and quality of services, and standardizing the number and distribution of manpower in clinical departments is necessary to improve the efficiency and quality of services provided to patients, the utilization of existing resources, and the efficiency of the hospital system [6, 7]. Therefore, work study will help managers better understand the cause of problems and issues related to manpower in their organization and take the actions necessary to improving procedures and reducing time of doing job due to enhance efficiency and productivity $[8,9]$.

The legal requirements emphasized in the third economic, social, and cultural program of the country's development (Seasons 1 and 2), regulating criteria for the governmental financial rules (Article 88), approvals of the Cabinet, and strategic policies of the Health Ministry (Chapters 9 and 11) suggest the establishment of a management system based on the performance of employees and operating budgets in organizations such as hospitals that emphasizes the establishment of a wage labor system (performance-wage) instead of daily wages. Undoubtedly, such a system will not deploy unless the process and time needs associated with each activity or task is determined. In this respect, the use of techniques such as work study and timing are very effective for increasing performance and improving effectiveness in an organization [10].

In previous studies, regarding the quantitative and qualitative survey of manpower in various parts of the health care system, it has been observed that the current forces are less than the manpower required in the same sector $[7,11]$. Some studies have observed opposite results, namely, that the number of existing forces is more in a section than the number of required manpower in the same sector $[5,12]$. Accordingly, the number of required 
manpower in various sectors of hospitals must be investigated. Among all hospital departments, laboratories have a particular importance because of the need for high quality and timely service within this section; thus, access to the required personnel in terms of quantity and quality in this sector has great importance. For that reason, this study estimated the number of manpower needed based on the work study and timing method in selected hospital laboratory units of Shiraz University of Medical Sciences.

\section{Objective}

This study investigated the manpower requirements of various units of the laboratory at the Shiraz Faghihi Hospital.

\section{Methods}

This research was a descriptive-analytical and practical cross-sectional study. The study population included all test procedures carried out in units of parasitology, hormone biology, microbiology and urinalysis in the laboratory of Shiraz Faghihi Hospital. The sampling was conducted as a census, and all said that process units were evaluated. The work study and timing method was used to estimate manpower requirements. The research was carried out in the following steps:

\subsection{Preparation of the Ordering of Main Activities of the} Units of Parasitology, Hormone Biology, Microbiology and Urinalysis

Direct observation, interviews with process owners, and surveys of staff job descriptions from parasitology, hormone biology, microbiology, and urinalysis units were used to prepare the list.

\subsection{Timing}

Returning timing to zero (discrete) was used in this study. In this timing method, chronometer hands by return gauge returns to zero at the end of each work element by returning gauge and allowing the needle to move once again. The timing of each work element is done independently; the clock never stops, and the hands move immediately to show the next time element.

\subsection{Computing of Performance Coefficient}

To compute the performance coefficient, the Westinghouse Method was used as described in the following:

Skill, attempt, consistency, and environmental conditions are the four determinant factors in the Westinghouse performance coefficient. The mediocrity rate (performance in standard level) was considered zero for all four factors. After observing and determining work time, the assessor extracted appropriate amounts from the table based on personal judgment, collected them with number one indicating the normal work and being equal with $100 \%$, calculated the performance index, and added it to the observation time [17] (Table 1).

\subsection{Determination of Normal Time}

Normal time was determined using the following formula: Normal time $=$ observation time $\times$ performance coefficient

\subsection{Determination of Allowed Rest Time}

The allowed rest time has two main sections:

Fixed Allowed Time, including:

A) Allowed times for meeting personal needs: The amount of fixed allowed time commonly used by institutions is between $5 \%$ and $7 \%$ [17], and that same amount was considered in this study.

B) Allowed time for main refreshment: The common rate for this is $4 \%$ of the base time [17], and this study calculated the same amount.

Table 1. Determination of performance coefficient based on Westinghouse method

\begin{tabular}{|c|c|c|c|c|c|}
\hline Effort & & & Skill & & \\
\hline \multirow{2}{*}{ Extraordinary } & $\mathrm{A} 1$ & +0.13 & \multirow{2}{*}{ Extraordinary } & A1 & +0.15 \\
\hline & A2 & +0.12 & & A2 & +0.13 \\
\hline \multirow[b]{2}{*}{ Excellent } & B1 & +0.10 & \multirow[b]{2}{*}{ Excellent } & B1 & +0.11 \\
\hline & B2 & +0.08 & & B2 & +0.08 \\
\hline \multirow{2}{*}{ Good } & $\mathrm{C} 1$ & +0.05 & \multirow{2}{*}{ Good } & $\mathrm{C} 1$ & +0.06 \\
\hline & $\mathrm{C} 2$ & +0.02 & & $\mathrm{C} 2$ & +0.03 \\
\hline Average & $\mathrm{D}$ & 0.00 & Average & $\mathrm{D}$ & 0.00 \\
\hline \multirow{2}{*}{ Appropriate } & E1 & -0.04 & \multirow{2}{*}{ Appropriate } & E1 & -0.05 \\
\hline & $\mathrm{E} 2$ & -0.08 & & E2 & -0.10 \\
\hline \multirow{2}{*}{ Weak } & F1 & -0.12 & \multirow{2}{*}{ Weak } & F1 & -0.16 \\
\hline & $\mathrm{F} 2$ & -0.17 & & $\mathrm{~F} 2$ & -0.22 \\
\hline Compatibility/Stability & & & Working Conditions & & \\
\hline Extraordinary & A & +0.04 & Extraordinary & A & +0.06 \\
\hline Excellent & B & +0.03 & Excellent & B & +0.04 \\
\hline Good & $\mathrm{C}$ & +0.01 & Good & $\mathrm{C}$ & +0.02 \\
\hline Average & D & 0.00 & Average & $\mathrm{D}$ & 0.00 \\
\hline Appropriate & $\mathrm{E}$ & -0.02 & Appropriate & $\mathrm{E}$ & -0.03 \\
\hline Weak & $\mathrm{F}$ & -0.4 & Weak & $\mathrm{F}$ & -0.07 \\
\hline
\end{tabular}

Variable Allowed Times: The following formula was used to estimate variable allowed times [17]:

Allowed time $=$ allowed coefficient percentage $\times$ normal coefficient

\subsection{Determining Standard Time}

The following formula was used to determine standard time:

Standard time $=$ all allowed additions + normal time

\subsection{Duration of Work Time in a Day}

Considering 5 hours of work per day for each employee, total working time equaled 300 minutes per day per employee. 


\subsection{Number of Observations per Person per Day}

The number of observations was obtained from the following formula:

Number of an employee's observations per day=observation time of each sample $\div$ maximum number of samples

\subsection{Determination of the Number of Required Manpower}

Manpower requirements for parasitology, hormone biology, microbiology, and urinalysis units of the laboratory at Faghihi Hospital was obtained using the following formula:

The number of manpower required $=$ number of observations per each person in a day $\div$ maximum number of samples

\section{Results}

The number of activities required to perform tests in parasitology were 10 , in hormone testing were 16 , in microbiology testing were 13 , and in urinalysis were 8 activities. The mean observation times for these tests were $9.48,3.55,7$, and 4 minutes, respectively (Table 2).

The maximum normal time between studied tests was related to the parasitology unit (10.60 minutes), and the minimum normal time was related to hormone biology (4 minutes). Consequently, the maximum standard time was related to the parasitology unit (11.63 minutes) and the minimum (4.4 minutes) was related to the hormone biology unit. The average standard times of each work cycle in the parasitology, hormone biology, microbiology, and urinalysis units were $12,5,9$, and 5 minutes, respectively (Table 3).

The manpower requirements of the studied hospital laboratory for parasitology, hormone biology, microbiology, and urinalysis units were $2.6,3,4$, and 3.7 people, respectively.

Table 2. Ordering of activities of each test in each of the units under study, observation numbers, and mean observation times

\begin{tabular}{|c|c|c|c|c|}
\hline Unit & Kind of Test & Order of Doing Activities of Each Test & $\begin{array}{c}\text { Observation } \\
\text { Times }\end{array}$ & $\begin{array}{c}\text { Observation Time } \\
\text { Mean (Minute) }\end{array}$ \\
\hline Parasitology & Parasite test & $\begin{array}{l}\text { 1. Numbering request forms transmitted from the admissions unit to this unit } \\
\text { 2. Numbering sample utensils based on request forms } \\
\text { 3. Preparing and numbering lams } \\
\text { 4. Numbering on A4 paper (preparation list) } \\
\text { 5. Cleaning position by alcohol } \\
\text { 6. Sampling and recording microscopic features } \\
\text { 7. Viewing sample under microscope } \\
\text { 8. Recording observations in a notebook } \\
\text { 9. Recording and reporting with the HIS system } \\
\text { 10. Checking printed reports }\end{array}$ & 13 & 9.48 \\
\hline $\begin{array}{l}\text { Hormone } \\
\text { biology }\end{array}$ & Hormone test & $\begin{array}{l}\text { 1. Checking requested forms with samples } \\
\text { 2. Centrifuges (twice blood sample and once serum sample) } \\
\text { 3. Dividing serum samples in pips } \\
\text { 4. Freezing } \\
\text { 5. Thawing frozen samples from previous day } \\
\text { 6. Sampling } \\
\text { 7. Adding test solution to samples } \\
\text { 8. Putting bungs on samples } \\
\text { 9. Putting samples in incubator/Ben Murray/shaker } \\
\text { 10. Washing sample } \\
\text { 11. Testing the accuracy of system performance } \\
\text { 12. Reading samples using system } \\
\text { 13. Numbering read tests regarding pipes' numbers } \\
\text { 14. Entering answers into work lists } \\
\text { 15. Entering answers into reporting system } \\
\text { 16. Checking reports with work lists }\end{array}$ & 57 & 3.55 \\
\hline Microbiology & Microbe test & $\begin{array}{l}\text { 1. Recording names in notebook } \\
\text { (For blood cultures, names and features are recorded in system, too.) } \\
\text { 2. Sampling } \\
\text { 3. Putting slew environment in incubator } \\
\text { 4. Separating positive and negative samples from incubator to read positive samples } \\
\text { 5. Reading positive samples } \\
\text { 6. Coding pipe slew circuits based on positive cultivate environment } \\
\text { 7. Further cultivation of micro-organisms in pipe circuits } \\
\text { 8. Viewing sample from lams } \\
\text { 9. Putting up solutions containing sample on slew circuits and applying antibiotics on } \\
\text { them } \\
\text { 10. Reading the samples after slew in pipe circuits and after applying antibiotics } \\
\text { 11. Reporting in HIS system } \\
\text { 12. Checking the printed reports } \\
\text { 13. Ordering prints based on the numbers }\end{array}$ & 19 & 7 \\
\hline Urinalyses unit & Urinalyses & $\begin{array}{l}\text { 1. Pouring sample in pipe and coding pages } \\
\text { 2. Using paper tape and microscopic record } \\
\text { 3. Observing certain weight for each sample } \\
\text { 4. Centrifuging samples at } 5 \text { minutes for every sample class } \\
\text { 5. Preparing lams } \\
\text { 6. Observing samples under microscope } \\
\text { 7. Reporting in HIS system } \\
\text { 8. Checking the printed reports }\end{array}$ & 80 & 4 \\
\hline
\end{tabular}


Table 3. Performance coefficient, normal time, additions allowed time, and standard time for doing activities in every studied unit

\begin{tabular}{lccccc}
\hline Unit & $\begin{array}{c}\text { Number of } \\
\text { Observations }\end{array}$ & $\begin{array}{c}\text { Coefficient of } \\
\text { Performance }\end{array}$ & $\begin{array}{c}\text { Normal Time } \\
\text { (Minutes) }\end{array}$ & $\begin{array}{c}\text { Allowed Time to Attend to } \\
\text { Personal Needs (Minutes) }\end{array}$ & $\begin{array}{c}\text { Allowed Time for } \\
\text { Refreshment (Minutes) }\end{array}$ \\
\hline Parasitology & 13 & $112 \%$ & 10.60 & 0.63 & 0.42 \\
Hormone biology & 57 & $115 \%$ & 4 & 0.24 & 0.16 \\
Microbiology & 19 & $117 \%$ & 8 & 0.48 & 0.32 \\
Urinalyses & 80 & $115 \%$ & $4 / 6$ & 0.27 & 0.18 \\
\hline
\end{tabular}

Table 4. Determined number of personnel required for each studied unit

\begin{tabular}{|c|c|c|c|c|c|c|c|}
\hline Unit & $\begin{array}{c}\text { Observation } \\
\text { Time of Each } \\
\text { Sample } \\
\end{array}$ & $\begin{array}{c}\text { Maximum } \\
\text { Number of } \\
\text { Samples }\end{array}$ & $\begin{array}{c}\text { Work Time } \\
\text { in a Day } \\
\text { (Minutes) }\end{array}$ & $\begin{array}{c}\text { Number of } \\
\text { Observations per } \\
\text { Person per Day }\end{array}$ & $\begin{array}{c}\text { Number of } \\
\text { Required } \\
\text { Personnel }\end{array}$ & $\begin{array}{c}\text { Number of } \\
\text { Existing } \\
\text { Workforce }\end{array}$ & $\begin{array}{c}\text { Difference of Required } \\
\text { and Existing Workforces }\end{array}$ \\
\hline Parasitology & 12 & 66 & 300 & 25 & 2.6 & 1 & 1.6 \\
\hline Hormone biology & 5 & 183 & 300 & 60 & 3 & 5 & -2 \\
\hline Microbiology & 10 & 125 & 300 & 30 & 4 & 5 & -1 \\
\hline Urinalyses & 5 & 226 & 300 & 60 & 3.7 & 4 & -0.3 \\
\hline
\end{tabular}

According to the existent manpower in these units, only the number of personnel in the urinalysis unit were proportional to the number of required personnel; the rest of the units faced either a surplus or a shortage of manpower. Overall, the laboratory department had 2 extra personnel (Table 4).

\section{Discussion}

Today, manpower is known as a dynamism and a factor of social development. It plays a pivotal role in organizations. All organizations realize manpower as a valuable factor in achieving an organization's goals [13]. It is well-known that the manpower of any society is the most important factor of production and the growth and development of any country depends on its manpower [14]. On this basis, considering the quantity and quality of manpower has much importance.

The study findings showed that the average standard time of each work cycle in parasitology, hormone biology, microbiology, and urinalysis units were 12, 5, 9, and 5 minutes. Extensive observation times in the parasitology unit may be caused by the large number of parasite types the presence or absence of which must be determined in the sample. The high observation times for microbe testing inevitably cause microbiology to be a lengthy process and requires the claw different stages; test procedures of hormone biology and urine analysis are easier and do not need the various stages of claw.

Asadi discusses in his research estimating the manpower requirements in the blood biochemistry and hematology units of Vali-Asr Health Center laboratory and Abade Imam Khomeini Hospital. The average standard time to perform CBC and CBC Diff tests in the hematology unit of Vali-Asr Health Center laboratory were respectively 469.09 and 116.8 seconds; the averages for these times in the hematology unit of Abade Imam Khomeini hospital lab were 735.2 and 128.9 seconds. The mean standard time of testing in the biochemistry unit of the health center lab was 299.3 seconds and in biochemistry unit of hospital lab was 141.34 seconds [15]. Brezmes et al. analyzed costs in a microbiology laboratory and estimated the average work time for each product to be 14.64 minutes. The total times that personnel and devices were actively performing testing was considered [16].

By taking 5 working hours per day (from taking samples to reporting answers), and the maximum number of samples in the first 6 months of the year 2012, the manpower required in the parasitology, hormone biology, microbiology, and urinalysis units were estimated to be 2.6, 3,4 , and 3.7 people, respectively. It was also estimated that there was one person too few in the parasitology unit, an excess of 2 people in the hormone biology unit, one extra person in the microbiology unit, and a proportionate number of people in the urinalysis unit. These results indicated that the 4 studied units, after manpower adjustments were made, are faced with 2 extra employees. Management can apply these people in other units that have a manpower shortage.

In a research conducted in Bushehr to review the qualitative and quantitative distribution of healthcare manpower, it was found that 14 laboratory professionals are required for this province, yet there were only two [13]. Akbari studied the impact of work survey project implementation on cleaning staff efficiency of Shiraz Faghihi Hospital and concluded that, in the studied parts, 72 people were required, but the number of existent manpower was 96 people. Clearly, there was a surplus in manpower of 24 people [17].

Khani in a study entitled "Evaluation, work survey and work division of corporative (service) manpower placed on Vali-Asr Hospital in Zanjan and offering new solutions" observed that the number of corporative manpower were 217 people before implementation of the project and new arrangement; afterward, the number of manpower reached 157 people [12]. Moreover, results of the 2010 study entitled "The estimating number of manpower required per reception Children's Medical Center of Tehran Medical Sciences University using the measurement and timing method of activities" indicated that the number of required manpower in this unit were about 11 people, while the number of existent staff in the unit were 9 people [18].

Mohammadi et al. in his study the Distribution of Manpower of Hospitals Affiliated to Kurdistan University of Medical Sciences in Accordance with Personnel 
Standards of the Ministry of Health and Medical Education, and the estimation results from about 62 departments of the studied hospitals and a comparison of the estimations and the current situation showed that, according to Health Ministry standards, only 7 departments $(11.29 \%)$ were in accordance with the manpower standard; 7 departments $(11.29 \%)$ were higher, and 48 departments $(77.42 \%)$ were below standard. The gap between available and required manpower in Imam Khomeini, Mustafa Khomeini, and Taleghani hospitals were estimated to be 16,14 , and 3 , respectively [19].

In their study entitled "Quantity optimizing of emergency unit's nurses in Ayatollah Kashani hospital using linear programming," Bagherian and Tadayon concluded that the minimum number of nurses needed to provide satisfactory services in the emergency unit of the studied hospital was 14 [20].

However, as reported by Ugwa, a leadership style which is participatory is required to ensure equitable distribution of these human resources so as to avoid trading employees satisfaction for performance [21]. Moreover, improvement of job satisfaction and working conditions could be achieved through effective regulation of working hours [22].

\section{Conclusion}

Results of the current study indicated that the four studied units have 3 surplus people after manpower adjustments. Overall, management can apply these employees in other departments which had manpower shortages. Therefore, because of the high organizational costs and problems made by lacks and surpluses of manpower, politicians and hospital managers should better use new, scientific tools to become aware of their organization's personnel situation, to help the organization's growth, and to avoid additional costs.

Also, considering global discussions regarding the quality of care and patients' waiting time, further research will be necessary to determine how waiting time can be further reduced especially in the microbiology laboratories.

\section{Acknowledgments}

The authors hereby sincerely thank all authorities and personnel in the laboratory of the Shiraz Faghihi Hospital who completely cooperated with the researchers.

\section{Authors' Contributions}

All authors have had an equal part in this paper.

\section{Conflict of Interest}

No conflicts of interest have been declared by the authors.

\section{References}

1. Ozcan S, Hornby P. Determining hospital workforce requirements: a case study. Hum Resour Dev J. 1999;3(3).

2. Michael A. A handbook of human resource management practice. Cambridge University Press, London. 2006.

3. Birch S, Kephart G, Murphy GT, O'Brien-Pallas L, Alder R, MacKenzie A. Health Human Resources Planning and the Production of Health: Development of an Extended Analytical Framework for Needs-Based Health Human Resources Planning. J Public Health Manag Pract. 2009;15(6):S56-S61. [DOI]

4. Melgar T, Schubiner H, Burack R, Aranha A, Musial J. A timemotion study of the activities of attending physicians in an internal medicine and internal medicine-pediatrics resident continuity clinic. Acad Med. 2000;75(11):1138-43. [DOI]

5. Hatam N, Moslehi Sh, Askarian M, Shokrpour N, Keshtkaran A, Abbasi M. The Efficiency of General Public Hospitals in Fars Province, Southern Iran. Iran Red Crescent Med J. 2010;2010(2):138-44

6. Lin CF, Kao CC. [Clinical nursing manpower: development and future prospects]. Hu Li Za Zhi. 2014;61(2):13-9.

7. Arab M, Tajvar M, Akbari F. Selection an appropriate leadership style to direct hospital manpower. Iran J Public Health. 2006;35(3):64-9.

8. Powers SK, Beadle RE, Mangum M. Exercise efficiency during arm ergometry: effects of speed and work rate. J Appl Physiol Respir Environ Exerc Physiol. 1984;56(2):495-9.

9. Hanft RS. Health manpower. Health care delivery in the United States: Springer Publishing Co New York; 1977. p. 67-91.

10. Dickerson C, Green T, Blass E. Workforce development and effective evaluation of projects. Br J Nurs. 2014;23(12):685-90. [DOI]

11. Brown MM, Brown GC, Sharma S, Hollands H, Smith AF Physician manpower and health care expenditures in the United States: a thirty-year perspective. J Health Care Finance. 2001;27(4):55-64.

12. Khani M, Askari L, Ganje-Khani M, Salman-Mohajer N. Study of services staff ergometer and division of work stable in Zanjan Valiasr hospital and and provide new strategies for deployment of forces. First National Conference on Hospital Resource Management; Tehran, 2002. Persian

13. Akbari F, Kokabi F. Determining nursing manpower needed in a sample hospital. Hosp J. 2011;9(3):69-76. Persian

14. Cleary BL, Rice R. Nursing workforce development: Strategic state initiatives: Springer Publishing Company; 2005.

15. Asadi L. Estimate requirement staff for blood biochemistry and hematology laboratory at the Department of Abadeh Health Center and Hospitals using work study. Tehran: Shiraz University of Medical Science; 2009. Persian

16. Brezmes M, Ochoa C, Eiros J. Cost analysis in a clinical microbiology laboratory. Eur $\mathbf{J}$ Clin Microbiol Infect Dis. 2002;21(8):582-8. [DOI]

17. Akbari S. Comparing cost efficiency Faghihi hospital in 2001 Tehran: Shiraz University of Medical Sciences; 2001. Persian

18. Arab M. Estimation of requirement staff number at Children's Medical Center. Tehran: Tehran University of Medical Sciences; 2010. Persian

19. Mohammadi K, Moradi S, Mahmoudi A, Arjouni S, Sohrabi M. Study the Distribution of Manpower of Hospitals Affiliated to Kurdistan University of Medical Sciences in Accordance with Personnel Standards of the Ministry of Health and Medical Education. Acad J Res Econ Manag. 2015;3(2):53-63.

20. Bagherian H, Tadayon H. Quantitative optimization of Ayatollah Kashani hospital emergency department nursing using linear programming. Sixth National Conference on Student Health Care Management; Tehran, 2009. Persian

21. Ugwa E. A cross-sectional study of job satisfaction and leadership styles among the nurses in Aminu Kano teaching hospital. Niger J Basic Clinl Sci. 2014;11(2):114.

22. Ugwa E, Muhammad LM, Ugwa CC. Job satisfaction among nurses and doctors in a Tertiary Hospital in North-Western Nigeria: a cross- sectional study. Int J Hosp Res. 2014;3(1):11-8. 